\title{
Sexually dimorphic behavior in group-housed rhesus monkeys (Macaca mulatta) at 1 year of age
}

\author{
JENNIFER LOVEJOY and KIM WALLEN \\ Yerkes Regional Primate Research Center and Department of Psychology \\ Emory University, Atlanta, Georgia
}

\begin{abstract}
Although laboratory studies suggest that sex differences expressed by juvenile rhesus monkeys are influenced by their social rearing environment, few studies have examined developmental sex differences under seminatural social conditions. We report sex differences in yearling rhesus macaques (Macaca mulatta) raised in a 69-member social group. Like laboratory-reared animals, males mounted and played more than did females. In contrast to the results of laboratory studies, there were no sex differences in aggression or submission, nor were there any sex differences in grooming or mother-yearling interactions. Yearling females approached and spent more time with adult, nonmother females and with younger infants than did yearling males. These findings suggest that male and female rhesus monkeys engage in juvenile patterns of behavior related to sexually dimorphic adult patterns of social behavior.
\end{abstract}

The life histories of male and female rhesus monkeys differ in a number of important respects that are related to the social structure of feral rhesus groups. Rhesus monkey society is based on stable matrilines maintained by sex-specific patterns of behavior (Altmann, 1962; Kummer, 1971; Lindburg, 1971). For example, females care for the young and maintain group cohesiveness through grooming and other affiliative behaviors. Males, on the other hand, are less involved in infant care and have been thought to display more aggressive behavior related to troop defense (Altmann, 1962; Lindburg, 1971)although the validity of this belief has been challenged, since some data show female rhesus monkeys to be no less aggressive than males (Smuts, 1987). Another sex difference in rhesus macaques is that males generally join a new troop after puberty, while females are integrated into the social structure of their natal group (Carpenter \& Nishimura, 1969; Colvin, 1986; Lindburg, 1969). Thus, as females grow up, they are incorporated into a kinship network that provides social support in adulthood. In contrast, the acceptance of adult males into a social group depends on social skills for alliance formation with nonkin (Lindburg, 1969). It is likely that juvenile males and females begin at an early age to develop skills that allow them to fulfill their adult roles, and that the adult skills necessary for males and females differ to some degree. Thus, the development of sex differences in

\footnotetext{
This research was supported in part by Grant $2-42860$, awarded to Kim Wallen by the Emory Research Council; NIH Grant RR-08006 awarded to D. R. Mann; and NIH Grant RR-00165, awarded by the Division of Research Resources to the Yerkes Regional Primate Research Center. The Yerkes Center is fully accredited by the American Association for Accreditation of Laboratory Animal Care. Requests for reprints may be sent to Jennifer Lovejoy, Department of Medicine, Emory University School of Medicine, 69 Butler St. S.E., Atlanta, Georgia 30303 .
}

juvenile social behavior is of considerable interest in helping to understand the social dynamics of rhesus groups.

From controlled laboratory studies, it has become apparent that sex differences result from an interaction between a specific rearing environment (Goldfoot, Wallen, Neff, McBriar, \& Goy, 1984; Goy \& Wallen, 1979) and an animal's prenatal hormonal milieu (Goy, 1978; Goy $\&$ Phoenix, 1971). However, the relative contributions of the rearing environment and the prenatal hormonal environment appear to vary with the specific behavior under study. Thus, some sexually dimorphic behaviors, such as mounting and rough play, occur consistently across a wide range of rearing conditions. In all the social conditions examined, young males mount more than young females and exhibit higher levels of rough-and-tumble play (Goldfoot et al., 1984; Goy, 1978; Harlow, 1962; Harlow \& Harlow, 1965). In contrast, other juvenile sex differences, such as aggression and passivity, are only found under specific social conditions. For example, when infants were weaned at birth, housed individually, and allowed limited access to peers, males were more aggressive and females more submissive (Cross \& Harlow, 1965). Comparable sex differences, which were not seen when mothers and their offspring were housed together continuously during the infant's first year of life, seem to be related to the amount and character of interactions with peers (Goy \& Wallen, 1979; Wallen, Goldfoot, \& Goy, 1981).

Surprisingly, even though adult females express several behaviors more frequently than adult males (Altmann, 1962; Lindburg, 1971; Spencer-Booth, 1968), studies of small laboratory groups generally have not found consistent patterns of behavior expressed more frequently by juvenile females (Goy \& Wallen, 1979; Goy, Wallen, \& Goldfoot, 1974; Harlow, 1962). Thus, most research on the expression of juvenile sex differences has focused on 
patterns displayed more frequently by males and on the hormonal and social determinants of their expression by both males and females. In contrast, field workers have suggested there may be patterns of behavior displayed more frequently by juvenile females, but these are only expressed in age-graded, socially complex groups (Berman, 1982, 1983; Eaton, Johnson, Glick, \& Worlein, 1985; Glick, Eaton, Johnson, \& Worlein, 1986).

One exception to the focus on juvenile male behavior in laboratory research has involved sex differences in caregiving behavior. The heightened attention of young females toward infants, a behavior known as "aunting" (Rowell, Hinde, \& Spencer-Boothe, 1964) or "allomothering'" (Nicolson, 1987), has been confirmed by several laboratory studies that have focused on the interactions of preadolescent rhesus monkeys with infants (Brandt \& Mitchell, 1973; Chamove, Harlow, \& Mitchell, 1967; Gibber \& Goy, 1985). These studies all suggest that female preadolescents spend more time engaged in positive social interaction (including ventral contact, sexual behavior, grooming, and play) with infants, while males show more hostility and aggression toward infants. Studies from the field are less clear, since the focus has not been on preadolescents; however, there is a suggestion that juvenile female rhesus monkeys engage in more care-giving behavior than male juveniles do (Breuggeman, 1973).

The interactions of infants with other animals, including juveniles, have been examined in more naturalistic situations. It has been suggested that infants' social networks mirror those of their mothers (Berman, 1982, 1983). Under seminatural conditions on Cayo Santiago, Puerto Rico, rhesus infants interacted more with females than males, and more with kin than nonkin for each age and kinship group examined (Berman, 1982). Berman's study focused on the infant's interactions, rather than on other animals' interactions with infants, and her duration data consisted of the proportion of instantaneous scans in which a given animal was interacting with an infant. Thus, although a greater proportion of these scans involved infants interacting with females, it was not clear who initiated the interaction. The specific question of sex differences in older juveniles' interactions with infants remained unanswered.

Eaton et al. (1985) studied group-living Japanese macaque (Macaca fuscata) infants from birth to 1 year of age and found that male infants play and mount more than females, while female infants groom and spend more time with other animals than males. The female infants in this study were also punished more by group members than were the male infants. Glick et al. (1986), reporting on the same population, found that both male and female infants interacted more with kin than nonkin, and more with females than males. Their data, which were reported in terms of the fraction of observation intervals during which an infant was recorded in proximity to another animal, did not address either who initiated the interaction or the identity of the animal with which the infant was interacting.

These studies suggest that there may be a difference between the patterns of social interaction of male and of female infants; the behavior of older juveniles, however, is unknown. In these studies, it is particularly interesting that the differences between male and female social interactions did not generally appear until the age of 6 months and that they progressively increased until the study ended with the monkeys at the age of 1 year. Thus, the interactions of yearling animals may be of considerable interest.

To date, most studies of sex differences in developing rhesus monkeys have been conducted under social conditions that differ markedly from the social environment of the free-ranging rhesus monkey. The limited number of studies of more socially complex macaque groups suggest a wider range of sexually dimorphic behavior than that reported on the basis of laboratory studies. However, the sampling methods employed and the age of the subjects studied leave many unanswered questions regarding the development of sexually dimorphic behavior in large social groups. In the present study, we observed 1 year-old animals born and raised in a large, age-graded, heterosexual social group, and we utilized a data collection technique that preserved the sequences, frequencies, and durations of behaviors.

\section{METHOD}

\section{Subjects and Housing}

Six male and 5 female rhesus monkeys (Macaca mulatta), born and raised in a 69-member social group formed in 1976 at the Yerkes Regional Primate Research Center field station in Lawrenceville, Georgia, were studied between 12 and 16 months of age. The social group consisted of 6 adult males, 15 adult females, 13 juveniles (2-5 years of age), 15 yearlings (1-2 years of age), and 20 infants (less than 1 year of age). The animals were housed in a $38 \times 38 \mathrm{~m}$ outdoor compound, with attached indoor housing and an animal handling area. The compound contained three climbing structures, as well as culverts where the animals could hide or find shelter. In addition, the ground inside the compound was graded, providing several levels that allowed the animals to isolate themselves visually from other group members. The animals were fed commerical food (Monkey Diet, Wayne Research Animal Diets) twice daily, supplemented with oranges. Water was freely available.

This social group was similar to a free-ranging group, in that all ages and sex groups were present and each member was free to interact with or avoid any other individual in the group. In addition, the adult male to female sex ratio $(1: 2.5)$ was comparable to that reported in the wild (Lindburg, 1971). As with natural groups, several different matrilines were present; they had been maintained since the group's formation. The subjects in the present study came from four different matrilines (out of six matrilines in the group), including high- and low-ranking lineages. In contrast to the more limited resources of natural groups, food and water were provided freely to the captive animals, though space was clearly more limited than it would be in a natural situation.

The male yearlings were used as control animals in another study that required weekly blood collection after behavioral observations were made on Friday. The entire group was run inside for blood 
collection from the males, who were lightly restrained and not anesthetized. The female yearlings were handled similarly to the males except that no blood sample was taken. To avoid potential disruption of behavioral observations, the blood collection was always done after the behavioral data collection on Friday, and the animals were not observed again until Monday morning. From Monday through Friday the animals were not handled or manipulated in any way, except that the doors to the indoor area were locked during observations to prevent animals from going out of view. All the animals were well habituated to the procedure; they had participated in the blood-collection procedure for 12 months prior to the start of behavioral observations.

\section{Behavioral Observations}

Each subject was observed for a total of $5 \mathrm{~h}$, by mean of a focal animal technique (Altmann, 1974). Data were collected for 12 weeks from May to August, 1984, between 0700 and $1030 \mathrm{~h}$. Group behavior during these hours was more active than during the afternoon heat; but it was representative of the patterns exhibited during the rest of the day, and it included one feeding session. The morning hours were selected to avoid the extreme afternoon heat, when most of the animals sought shade and slept until sunset. Each focal observation lasted $25 \mathrm{~min}$, and each subject was observed on an average of once a week. Five focal observations were made each day. The order of observations was randomized, with the constraint that no animal was observed again until all other subjects had received one test. The tests were generally conducted 3 days per week, but because no observations were done in rain or fog, the number of tests per week was not constant, ranging from 10 to 20 .

All interactions between yearlings and other animals were recorded in an actor:behavior:recipient:time-of-occurrence format. Data were recorded using a portable electronic computer (Radio Shack TRS80 Model 100) capable of time-tagging behaviors to $1 \mathrm{sec}$, and of providing sequences, frequencies, and true durations. All behavioral data were collected by an observer who sat in a tower above the compound. This position provided an unimpeded view of all areas of the compound.

\section{Behavioral Definitions}

A behavioral lexicon of 37 behavioral patterns was used for collecting data. The definitions used were as follows:

Mount-Combined double-footclasp and no-footclasp mounts (see Goy et al., 1974).

Present-Orient hindquarters toward another and deviate tail (see Wallen et al., 1981).

Rough play-Combined category including rough-and-tumble play and brief contact play, as defined in Goy et al. (1974).

Groom-As in Altmann (1962).

Threat-Open-mouthed, woofing threat (see Wallen et al., 1981). Withdraw-Rapid retreat from the approach of another animal.

Fear grimace-Submissive facial expression, as defined in Wallen, Bielert, \& Slimp (1977).

Display_Vigorous shaking of bars or jumping.

Restrain infant-Physical restraint of an infant by a yearling, usually by clutching to the ventrum.

Contact-Direct contact with another animal apart from play (may involve "cuddling," as defined in Spencer-Booth, 1968).

Proximity (Prox)-Sit or stand within $20 \mathrm{~cm}$ of another animal.

Near-Sit or stand within 1-2 $\mathrm{m}$ of another animal.

Total activity - Combined frequency measure of all behaviors initiated by the yearling, including solitary behaviors and interactions with others.

For data converted to proportions of total behaviors (see Results), several categories of combined behaviors were used:
Approach others-All approaches to proximity, and near. Sex-Initiating and receiving mounts and presents.

Play-Initiating and receiving rough play.

Follow-Closely follow any other animal.

Groom-Give and receive grooming.

Aggress/Submit-Threats given and received, withdrawal, display, and fear grimace.

\section{Data Analysis}

Cumulative frequencies and durations for each behavior were calculated for the $5 \mathrm{~h}$ of testing per animal. Totals were converted to rates per hour for data analysis. Males and females were compared using an independent-group $t$-test with 9 degrees of freedom. Differences across sessions were not compared, since we were not interested in temporal changes during this time and there was no reason to believe that significant changes would occur across a 12week period in animals of this age. A conservative $p$ value of less than or equal to .01 was considered significant.

\section{RESULTS}

The results for sexual behavior, grooming, rough play, and agonistic behavior are shown in Table 1 . In accord with results from other social environments, the males displayed significantly more mounts than did the females, and they also initiated and received rough play significantly more frequently. To determine whether these differences were the result of greater activity on the part of the males, we analyzed overall activity levels as the sum of all behavioral frequencies. There was no sex difference in overall activity [for males, $M \pm S E=105.9 \pm 56.9$; for females, $M \pm S E=97.8 \pm 24.8 ; t(9)=0.6]$.

There were no differences between males and females on any measures of agonistic behavior, including giving or receiving threats, withdrawal from other animals, display, or fear grimacing (Table 1). Certain stereotypically "timid" behaviors, such as rigidity or the "passive posture" described by Harlow and Harlow (1965) as prototypical infant female behaviors, were never observed in either sex. Contrary to the results of previous studies, there were no differences between males and females in total grooming behavior. When grooming was analyzed according to the category of animal being groomed,

Table 1

Mean Frequency per Hour $( \pm S E)$ of Selected Behaviors in Group-living Male and Female Yearling Rhesus Monkeys

\begin{tabular}{lrlll}
\hline \multicolumn{1}{c}{ Behavior } & \multicolumn{1}{c}{ Male } & \multicolumn{1}{c}{ Female } & \multicolumn{1}{c}{$t$} & \multicolumn{1}{c}{$p$} \\
\hline Mounts initiated & $0.8 \pm 0.1$ & 0.0 & 7.0 & $<.0001$ \\
Mounts received & $0.2 \pm 0.1$ & $0.6 \pm 0.3$ & 1.6 & \\
Presents & $1.3 \pm 0.3$ & $1.8 \pm 0.5$ & 1.0 & \\
Play initiated & $12.3 \pm 2.3$ & $3.9 \pm 0.7$ & 3.2 & 0.01 \\
Play received & $11.8 \pm 2.0$ & $4.7 \pm 0.7$ & 3.1 & 0.01 \\
Groom & $2.6 \pm 0.7$ & $2.6 \pm 0.8$ & 0 & \\
Receive groom & $3.2 \pm 1.9$ & $4.2 \pm 2.3$ & 0.8 & \\
Give threat & $0.3 \pm 0.6$ & $0.2 \pm 0.1$ & 0.4 & \\
Receive threat & $0.8 \pm 0.1$ & $1.0 \pm 0.2$ & 1.0 & \\
Withdraw & $6.9 \pm 0.9$ & $4.2 \pm 1.4$ & 1.7 & \\
Fear grimace & $1.1 \pm 0.5$ & $2.0 \pm 0.7$ & 1.1 & \\
Display & $1.3 \pm 0.5$ & $0.3 \pm 0.1$ & 1.7 & \\
\hline
\end{tabular}

Note- $d f=9$ for all $t$. 
Table 2

Mean Frequency per Hour $( \pm S E)$ of Approaches to Other Animals by Male and Female Yearling Rhesus Monkeys

\begin{tabular}{lrrrr}
\hline \multicolumn{1}{c}{ Behavior } & \multicolumn{1}{c}{ Male } & \multicolumn{1}{c}{ Female } & \multicolumn{1}{c}{$t$} & \multicolumn{1}{c}{$p$} \\
\hline Approach mother & $18.8 \pm 4.5$ & $17.3 \pm 2.1$ & 0.3 & \\
Prox mother & $14.3 \pm 4.2$ & $12.3 \pm 2.5$ & 0.4 & \\
Near mother & $5.0 \pm 0.8$ & $5.8 \pm 0.5$ & 0.8 & \\
Approach adult female (total) & $7.6 \pm 1.2$ & $14.3 \pm 1.9$ & 3.1 & 0.01 \\
Prox adult female & $2.6 \pm 0.6$ & $4.2 \pm 0.7$ & 1.7 & \\
Near adult female & $4.8 \pm 0.8$ & $10.2 \pm 1.3$ & 3.5 & 0.006 \\
Approach adult male (total) & $8.3 \pm 1.7$ & $9.2 \pm 0.8$ & 0.5 & \\
Prox adult male & $4.3 \pm 1.3$ & $3.6 \pm 0.7$ & 0.4 & \\
Near adult male & $4.0 \pm 0.6$ & $5.6 \pm 0.4$ & 2.1 & \\
Approach infant (total) & $4.1 \pm 0.9$ & $12.5 \pm 0.8$ & 8.6 & $<.0001$ \\
Prox infant & $2.9 \pm 0.8$ & $8.6 \pm 1.1$ & 4.2 & 0.002 \\
Near infant & $1.2 \pm 0.2$ & $3.6 \pm 0.4$ & 6.0 & 0.0001 \\
Contact infant & $0.8 \pm 0.5$ & $4.4 \pm 1.7$ & 2.2 & \\
Approach other yearling & $10.4 \pm 1.9$ & $11.7 \pm 1.3$ & 0.5 & \\
Prox yearling & $8.8 \pm 1.2$ & $8.7 \pm 0.8$ & 0.0 & \\
Near yearling & $9.2 \pm 1.1$ & $10.2 \pm 1.6$ & 0.3 & \\
\hline
\end{tabular}

Note- $d f=9$ for all $t$.

yearling males were found to groom adult males more frequently than they groomed any other class of animal. However, the frequency was not significantly different from that for yearling females [for males, $M \pm S E=$ $1.1 \pm 0.5$; for females, $M \pm S E=0.3+0.2 ; t(9)=1.3$ ] Neither male nor female yearlings spent much time grooming nonmother adult females [for males, $M \pm S E=$ $0.1 \pm 0.1$; for females, $M \pm S E=0.1 \pm 0.1 ; t(9)=0.09$ ]

The males and females differed significantly in approaches to other animals (Table 2). The total approaches to infants by females were significantly greater than those by males. Separate analysis of approaches in terms of the distances at which the approach ended revealed that the females approached infants to proximity and were near infants significantly more often than the males were. The females also tended to restrain infants more often than did the yearling males, although not significantly more [for males, $M \pm S E=0.5 \pm 0.2$; for females, $M \pm S E=$ $1.9 \pm 0.4 ; t(9)=2.94, p=.02]$. In accord with previous studies, infants tended to approach yearling females at higher frequencies than they approached yearling males; however, the difference was not significant $[M \pm S E=$ $3.3 \pm 0.6$ for males; $M \pm S E=5.8 \pm 0.8$ for females; $t(9)$ $=2.5, p=.03$ ]. Although the specific identities of the infants in these interactions were not recorded, the males and females were similar in having infant siblings in the group. All the female yearlings and 4 of 6 male yearlings had infant siblings.

Yearling females also approached adult, nonmother females significantly more often than did males (Table 2 ). These approaches included only those directed solely to the nonmother adult female and did not include cases where the yearling simultaneously approached its mother and another adult female. When approaches to adult females were analyzed according to distance category, the only significant difference occurred in approaches to 1-2 m. In contrast to results from earlier studies, no interactions with the mother, including approach to mother, grooming, punishing, and restraint by the mother, were significantly different between males and females (Table 3).

The differences between yearling male and female interactions with other nonmother animals are also apparent in the duration data (Table 4). The yearling females spent more total time with infants and more time near and in direct contact with infants than did the yearling males. In addition, the yearling females spent significantly more total time with adult nonmother females and more time within 1-2 $m$ of adult females (i.e., near them). All distance categories showed trends toward yearling females spending more time with adult females than yearling males did. In addition to spending more time near adult females,

Table 3

Mean Frequencies per Hour $( \pm S E$ ) for Interactions between Yearling Rhesus Monkeys and Their Mothers

\begin{tabular}{lrrrr}
\hline \multicolumn{1}{c}{ Behavior } & Males & Females & $t$ & $p$ \\
\hline Contact mother & $2.9 \pm 1.3$ & $0.9 \pm 0.3$ & 1.3 & - \\
Groom mother & $0.8 \pm 0.3$ & $0.6 \pm 0.3$ & 0.3 & - \\
Mother groom yearling & $1.9 \pm 0.7$ & $2.3 \pm 0.7$ & 0.4 & - \\
Mother restrain yearling & 0 & 0 & - & - \\
Mother threaten yearling & 0 & $0.2 \pm 0.1$ & 1.8 & - \\
\hline
\end{tabular}

Note- $d f=9$ for all $t$. 
Table 4

Mean Duration (in min) Spent with Other Animals (per 5-h test $\pm S E$ ) by Male and Female Yearling Rhesus Monkeys

\begin{tabular}{lcccc}
\hline \multicolumn{1}{c}{ Behavior } & Males & Females & $t$ & $p$ \\
\hline Within 2 m of mother & $87.3 \pm 17.8$ & $90.3 \pm 13.9$ & 0.5 & - \\
Proximity to mother & $40.1 \pm 12.3$ & $49.7 \pm 9.3$ & 0.6 & - \\
Near mother & $19.9 \pm 3.0$ & $25.9 \pm 2.1$ & 1.5 & - \\
Within 2 m of adult female & $56.2 \pm 4.9$ & $82.8 \pm 6.6$ & 3.3 & 0.009 \\
Proximity to adult female & $22.3 \pm 5.1$ & $27.8 \pm 4.6$ & 0.8 & - \\
Near adult female & $31.6 \pm 2.9$ & $54.7 \pm 5.5$ & 3.8 & 0.004 \\
Within 2 m of adult male & $42.2 \pm 6.0$ & $42.7 \pm 6.1$ & 0.1 & - \\
Proximity to adult male & $21.6 \pm 3.9$ & $13.1 \pm 3.4$ & 1.6 & - \\
Near adult male & $19.3 \pm 2.3$ & $29.3 \pm 3.5$ & 2.5 & 0.03 \\
Within 2 m of infant & $22.7 \pm 4.8$ & $45.2 \pm 5.0$ & 3.2 & 0.01 \\
Proximity to infant & $13.5 \pm 3.5$ & $26.5 \pm 6.1$ & 1.9 & - \\
Near infant & $8.7 \pm 1.3$ & $16.8 \pm 1.6$ & 3.9 & 0.003 \\
In contact with infant & $0.4 \pm 0.2$ & $1.8 \pm 0.5$ & 2.9 & 0.02 \\
Within 2 m of yearling & $40.6 \pm 6.9$ & $32.6 \pm 1.6$ & 1.0 & - \\
Proximity to yearling & $14.4 \pm 2.0$ & $13.2 \pm 1.4$ & 0.5 & - \\
Near yearling & $23.8 \pm 4.8$ & $19.0 \pm 2.3$ & 0.8 & - \\
\hline
\end{tabular}

Note $-d f=9$ for all $t$.

yearling females tended to spend more time within 1-2 m of adult males, although the difference was of borderline statistical significance and no other distance category showed this effect. There were no sex differences for durations of time spent with mother or peers (Table 4).

To facilitate an understanding of yearling behavior, we compared the distributions of male and female behaviors. These distributions were calculated as the frequency of each behavior, expressed as a percentage of the total behavior performed by the yearling. This method allowed for the construction of behavioral profiles for the "average" male and female yearling (Figure 1). Yearling females spent the greatest percentage of their total behavior in approaching other animals $(60 \%)$, which was greater than for males $(46 \%)$, although not statistically significant $[t(9)=7.3, p=.02]$. Yearling males spent a significantly greater percentage of their total behavior engaged in play $(25.5 \%)$, compared with females $(12 \%)$ : $[t(9)=10.2, p=.01]$. There was no difference between males and females in the percentage of aggression and submission, following, sexual behavior, or restraint of infants.

Because there was such a large difference between yearling male and female approach behaviors, we investigated the distribution of nonapproach behavior by recalculating total behavior, after having removed approaches to other animals (Figure 2). Almost half of the male's nonapproach behavior involved play (48\%), compared with only $29 \%$ of the female's behavior; however, this difference was not statistically significant $[t(9)=3.7$, $p=.09]$. For the females, a significantly greater percentage of nonapproach behavior involved restraining infants $[t(9)=13.2, p=.005]$. There were no differences between males and females in the percentage of total nonapproach behavior spent in aggression, following, grooming, or sexual behavior.
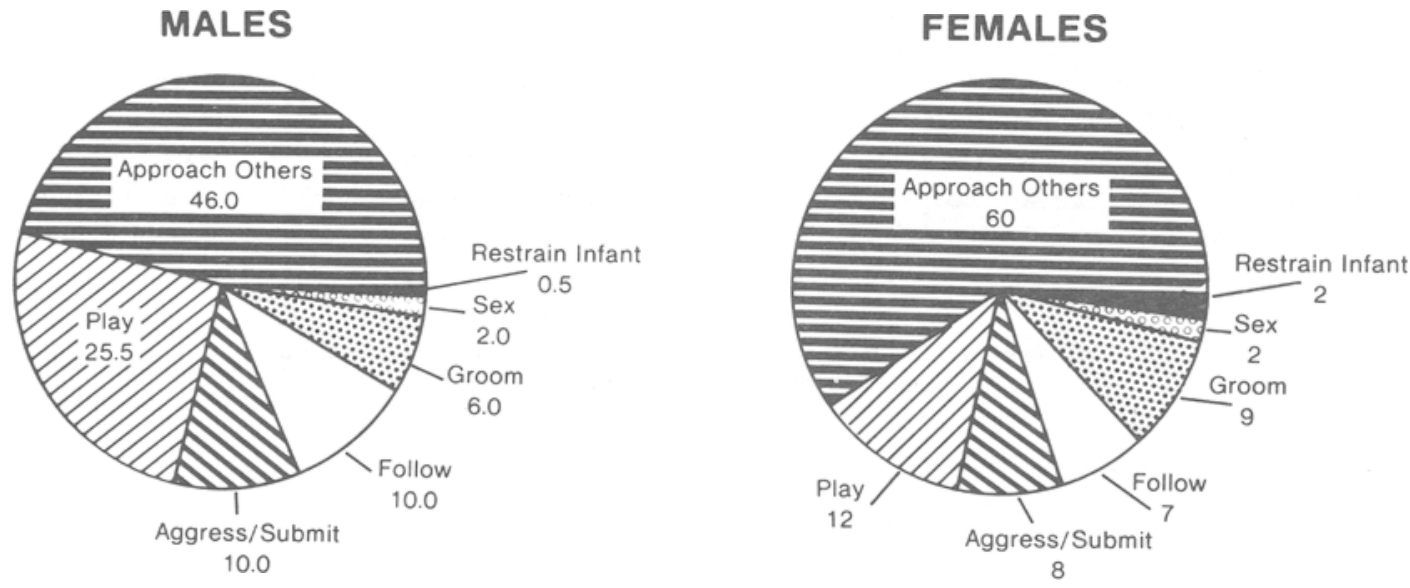

Figure 1. Distribution of male and female rhesus yearling behavior, with each behavioral category expressed as a percentage of total yearling behavior. The numbers beneath the behavioral categories are the percentages of total behavior expressed by that category. 

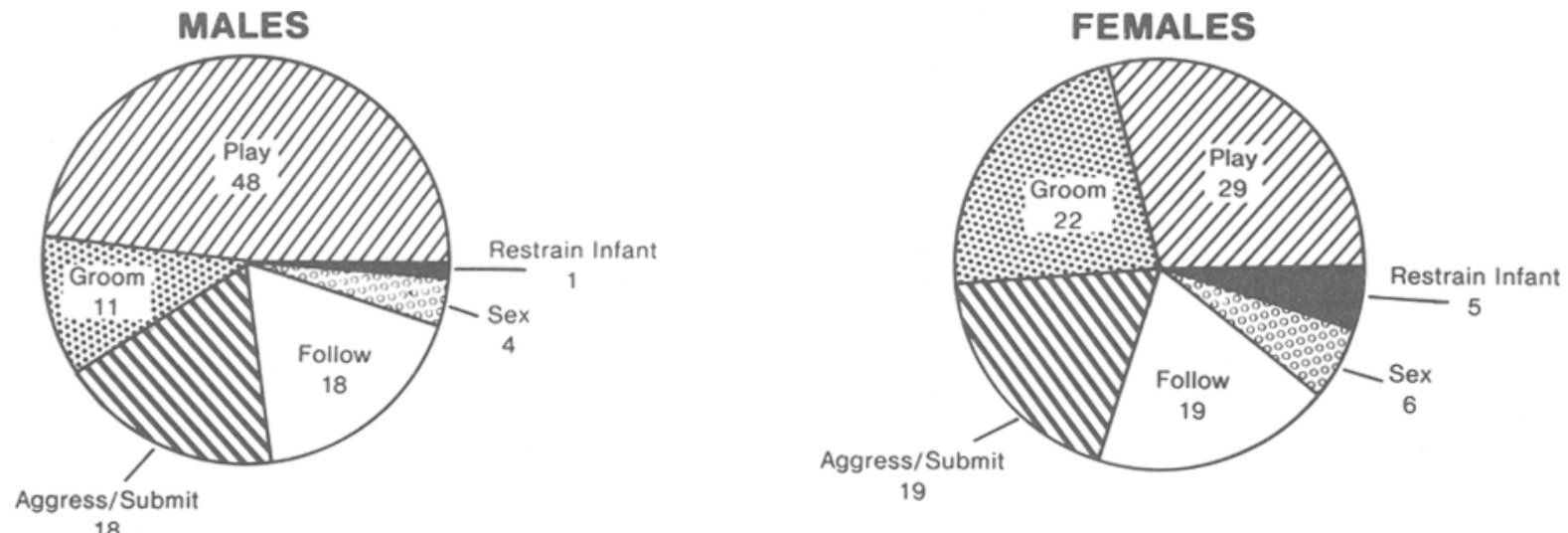

18

Figure 2. Distribution of male and female rhesus yearling nonapproach behavior. Each behavior is expressed as a percentage (the number under the behavioral category) of total nonapproach behavior. Restrain infant is significantly different between males and females $(p=.005)$.

Finally, the distributions of yearling approaches to other animals by age, sex class, and final distance were analyzed separately as percentages of total approach behavior (Figure 3). A greater percentage of female approaches went to within $20 \mathrm{~cm}$ of infants (14\%), compared with that for males $(6 \%)[t(9)=7.7, p=.02]$. But no approach percentage differed significantly between males and females.

\section{DISCUSSION}

Our results confirm the findings of earlier studies that have shown mounting and play to be sexually dimorphic under a variety of social conditions. These behavioral patterns are also influenced by prenatal androgens (Goy, 1978; Goy \& McEwen, 1980), and it appears that, unless the hormonal environment is manipulated, young males mount and play at higher frequencies than young females, regardless of social rearing. In contrast, presenting and aggression/submission, which are sexually dimorphic in yearlings under restricted social conditions (Cross \& Harlow, 1965; Goldfoot et al., 1984; Harlow, 1962), were not dimorphic in animals observed in a large social group. These findings support the notion that the expression of sexually dimorphic behavior results from an interaction between biology and the early social environment, with some behaviors being strongly biologically determined, and others strongly influenced by the rearing environment.

Our observation that yearling females initiate and maintain contact with infants extends the observations of Berman (1982) that juvenile rhesus females are more often found in proximity to infants. We have also demonstrated that differences between males and females exist for both
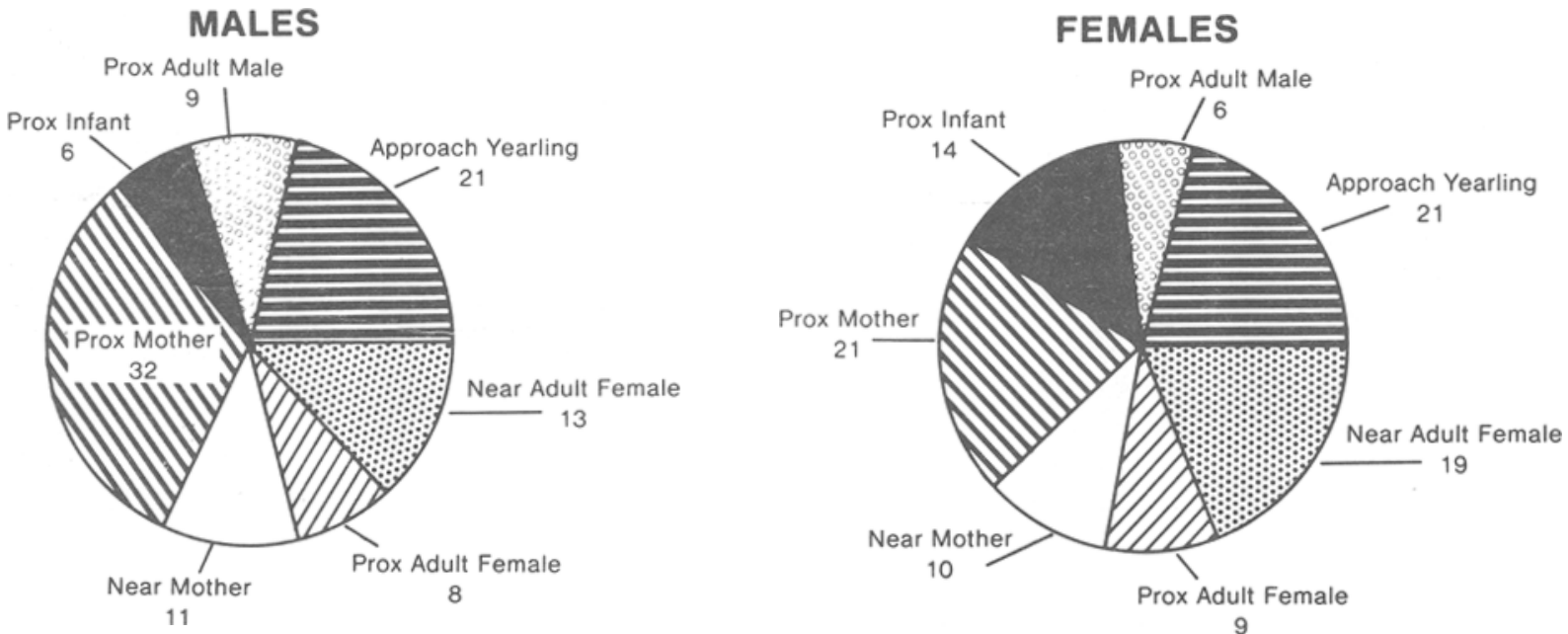

Figure 3. Distribution of male and female rhesus yearling approaches to other animals, analyzed by age and sex class of animal approached and final distance reached. There are no significant differences between males and females. The numbers under the behavioral categories are the percentages of total approaches expressed by that category. 
the frequencies and durations of contact with infants. This sex difference is apparently independent of interactions with the mother, since no sex differences between males and females exist for mother-yearling interactions in the variables measured. Additionally, there was no difference between males and females with respect to whether they had younger siblings present, and therefore it is unlikely that the effect is simply due to the fact that the females were interacting with siblings, and that the yearling males did not have siblings to interact with.

The focus of young females' attention on infants has been suggested to be important for the development of later maternal skills (Lancaster, 1971; Nicolson, 1987). Juvenile female vervet monkeys that live in the wild carry and cuddle small infants, an experience that may provide them with the motor skills necessary for later maternal behavior, as well as give them exposure to the maternal role (Lancaster, 1971). It is likely that this experience is similarly useful for a yearling rhesus monkey. There may be additional explanations for this behavior in the yearling female, however. Since these females do not play as often with their peers, it is possible that they regard infants as companions with a more compatible play style. Although we found no difference between males and females with respect to the frequency of play directed specifically toward infants, Lancaster (1971) has suggested that "mothering" types of behavior (such as restraint of infants and ventral contact) may be a different form of play that is expressed by females, rather than the rougher forms displayed by males. She further suggests that this pattern of play may be parallel to young girls' playing with dolls or younger siblings rather than participating in the rougher play of young boys (Maccoby \& Jacklin, 1974). It seems likely that play with infants would provide both educational and social benefits to young females.

The finding that yearling females specifically approach and sit with adult, nonmother females, independent of interactions with their mothers, has to our knowledge not been previously reported. However, this observation is consistent with data on younger infant rhesus and Japanese macaques reported by Berman (1982) and Eaton et al. (1985). Results from these two studies show that infant macaques interact more with females than males, and more with kin than nonkin. Unfortunately, our data did not preserve information on the kinship relation of the yearlings and the nonmother adult females with whom they were associating. On the basis of previous studies, however, it would seem likely that the adult females were closely related to the yearlings (Berman, 1982; Glick et al., 1986). The males and females in our study were balanced with regard to rank of their maternal lineage, and of the four matrilines represented by our subjects, three had both male and female yearlings represented. It is thus unlikely that our results stem from the fact that the yearling females came from larger or more dominant matrilines.

Regardless of the importance of kinship in determining association patterns, it is clear that female-female bonding develops at an early age in these animals. Previous authors have suggested that female-female bonding develops because young females are involved in more grooming interactions (Poirier, 1977; Seyfarth, 1980). Contrary to what has been observed in other studies (Eaton et al., 1985; Mitchell, 1979; Poirer, 1977), we found little evidence of higher frequencies or durations of grooming by young females as opposed to young males, and, particularly, very little grooming by either sex of adult females other than the mother. There is a suggestion that a greater proportion of the females' behavior involves grooming, but the overall differences in grooming behavior are slight and do not appear to be responsible for maintaining these female association patterns.

Observations of feral populations of rhesus monkeys suggest that female-female bonding is important to social structure. In the wild, females generally remain with their natal group for life and become integrated into the matrilineal hierarchy, while males leave their natal group and are integrated into another group (Carpenter \& Nishimura, 1969; Lindburg, 1969). Thus, social relationships between young females and adults are important for the social integration of the younger females into the social matrix. These relationships may later be important in forming alliances in intratroop aggression or for maintaining rank relationships.

Because of the structure of rhesus society, females obtain greater potential benefits from forming specific social relationships within the group where they will spend the rest of their lives. Males, on the other hand, presumably gain more from developing social skills that can be used to facilitate their introduction into a novel group. These skills may be learned from interactions with peers or with adult males, but the type of social bonds necessary for female integration into the natal group would be of little potential long-term benefit to the male. Although adult males do develop relationships with young males, it has been suggested that such relationships serve more to protect the young males while they remain in the group (Colvin, 1986). Adult-male-juvenile-male relationships are more likely to be initiated by the juveniles than by the adults, which suggests that the juveniles thereby gain some advantage (Vessey \& Meikle, 1984).

Previous work has shown the importance of early social history in the development of sex differences in the rhesus monkey (Goldfoot et al., 1984; Harlow, 1962). The present study extends this work by demonstrating similar sexually dimorphic patterns in a social environment more complex than those previously employed. In addition, this study reveals evidence for several patterns of behavior that are expressed more frequently by young females than by males. Eaton et al. (1985) has suggested that early sex differences in Japanese macaques presage patterns seen in adults. Similarly, in the rhesus monkey, these differential patterns of behavior appear to be tightly linked to the matrilineal social organization of rhesus troops. It is therefore possible to observe such sex differ- 
ences only in social groups with a long history, where all classes of age and sex are available for yearlings to interact with. Although our captive social group cannot be considered comparable to a wild group, it provides evidence similar to that obtained from wild groups, and it extends our understanding of the development of sexually dimorphic behavior beyond that obtainable from small, short-term social groups studied in the laboratory. In addition, these results suggest that an understanding of the development of juvenile sex differences in behavior will require an assessment of the relationship between juvenile behavior and adult patterns of behavior within the same individuals.

In many studies of human behavior, attempts have been made to draw parallels between behavior in nonhuman primates and in humans, and it is fair to ask this question in the context we have presented here. Examination of the literature on human sex differences shows that, in general, our data are quite consistent with reports of human sex differences in development.

Although it has been suggested that boys are more aggressive than girls, and that there may be a biological predisposition for this difference (Maccoby \& Jacklin, 1974), later critiques have suggested that reexamination of the data does not indicate a strong sex difference in aggression (Tieger, 1980). Under some circumstances and for some types of behavior (e.g., verbal aggression), girls are more aggressive than boys (Tieger, 1980). These observations fit well with the observation that in nonhuman primates, differences in aggressive behavior between juvenile males and females occur only in limited social contexts. In socially complex situations, such as those reported here, there are no sex differences in nonhuman aggression. Recent research (Strayer, Leclerc, \& Blicharski, 1987) on preschool children in Canada has demonstrated that although boys exhibited higher per hour rates of aggression for some behaviors, there were no differences between boys and girls in the relative rates of these behaviors. The authors suggest that the boys' higher activity level was the main factor influencing the findings, and that it is inaccurate to conclude that boys are more aggressive than girls at this age.

The question of affiliative interactions in children has been addressed recently by La Freniere, Strayer, \& Gauthier (1984). These researchers, employing behavioral methods developed by primatologists for field research, have shown that, for a certain period of development, both girls and boys tend to have exclusively same-sex interactions. This parallels both field work and laboratory studies that have consistently shown nonhuman primate males as giving and receiving more play behavior, which suggests that same-sex peers may predominate for at least a part of development. Strong parallels between human behavior and the development of social bonds in nonhuman primates ought not to be expected, since the types of bonds developed in nonhuman primates are thought to be strongly influenced by societal patterns. In rhesus mon- keys, for example, where males emigrate, female-female bonds are primary, while in chimpanzees, where females tend to emigrate, male-male bonds are more important (Smuts, 1987). According to this model, children in human society would not bond more strongly with either sex, since other social bonds are important.

In conclusion, although it is important not to extrapolate excessively from nonhuman primate research to human behavior, studies of captive nonhuman primates under conditions that approximate many of the social and environmental conditions of naturally living societies do provide closer parallels to human behavior than studies of rhesus monkeys reared under more restricted conditions. Ideally, this environment, which permits detailed and controlled observation of behavior, will allow us to test hypotheses relevant to the development of human behavior under ecologically meaningful conditions.

\section{REFERENCES}

Altmann, S. A. (1962). A field study in the sociobiology of rhesus monkeys, Macaca mulatta. Annals of the New York Academy of Sciences, 102, 338-435.

AltmanN, J. (1974). Observational study of behavior: Sampling methods. Behavior, 29, 227-267.

BERMAN, C. M. (1982). The ontogeny of social relationships with group companions among free-ranging infant rhesus monkeys: I. Social networks and differentiation. Animal Behaviour, 30, 149-162.

Berman, C. M. (1983). Differentiation of relationships among rhesus monkey infants. In R. A. Hinde (Ed.), Primate social relationships (pp, 89-93). Sunderland, MA: Sinauer.

Brandt, E. M., \& Mitchell, G. (1973). Pairing preadolescents with infants (Macaca mulatta). Developmental Psychology, 8, 222-228.

Breuggeman, J. A. (1973). Parental care in a group of free-ranging rhesus monkeys (Macaca mulatta). Folia Primatologica, 20, 178-210.

CARPENTER, C. R., \& NishimURA, A. (1969). The Takasakiyama colony of Japanese macaques (Macaca fuscata). In C. R. Carpenter (Ed.), Proceedings of the Second International Congress of Primatology: Vol. 1. Behaviour (pp. 16-30). New York: S. Karger

Chamove, A., Harlow, H. F., \& Mitchell, G. (1967). Sex differences in the infant-directed behavior of preadolescent rhesus monkeys. Child Development, 38, 329-335.

Colvin, J. D. (1986). Proximate causes of male immigration at puberty in rhesus macaques. In R. G. Rawlins \& M. J. Kessler (Eds.), The Cayo Santiago macaques: History, behavior and biology (pp. 131153). Albany, NY: SUNY Press.

Cross, H. A., \& Harlow, H. F. (1965). Prolonged and progressive effects of partial isolation on the behavior of macaque monkeys. Journal of Experimental Research on Personality, 1, 39-49.

Eaton, G. G., Johnson, D. F., Glick, B. B., Worlein, J. M. (1985). Development in Japanese macaques (Macaca fuscata): Sexually dimorphic behavior during the first year of life. Primates, 26, 238-248

GiBBER, J. R., \& GoY, R. W. (1985). Infant-directed behavior in young rhesus monkeys: Sex differences and the effects of prenatal androgens. American Journal of Primatology, 8, 225-237.

GLick, B. B., EATON, G. G., Johnson, D. F., \& Worlein, J. (1986). Social behavior of infant and mother Japanese macaques (Macaca fuscata): Effects of kinship, partner sex and infant sex. International Journal of Primatology, 7, 139-155.

Goldfoot, D. A., Wallen, K., NefF, D. A., McBriar, M. C., \& GoY, R. W. (1984). Social influences on the display of sexually dimorphic behaviour in rhesus monkeys: Isosexual rearing. Archives of Sexual Behavior, 13, 395-412.

GoY, R. W. (1978). Development of play and mounting behaviour in 
a female rhesus virilized prenatally with esters of testosterone and dihydrotestosterone. In J. D. Chivers \& J. Herbert (Eds.), Recent Advances in Primatology (Vol. 1, pp. 449-462). London: Academic Press.

Gor, R. W., \& MCEWEN, B. S. (1980). Sexual differentiation of the brain. Cambridge, MA: MIT Press.

GoY, R. W., PHOENIX, C. H. (1971). The effects of testosterone propionate administered before birth on the development of behaviour in genetic female thesus monkeys. In C. H. Sawyer \& R. A. Gorski (Eds.), Steroid hormones and brain function (pp. 193-201). Berkeley: University of California Press.

GoY, R. W., \& WLLEN, K. (1979). Experiential variables influencing play, foot-clasp mounting and adult sexual competence in male rhesus monkeys. Psychoneuroendocrinology, 4, 1-12.

GoY, R. W., WalleN, K., \& GoldFoot, D. A. (1974). Social factors affecting the development of mounting behavior in male thesus monkeys. In W. Montagna \& W. A. Sadler (Eds.), Reproductive behavior (pp. 223-247). New York: Plenum Press.

HaRLow, H. F. (1962). The heterosexual affectional system in monkeys. American Psychologist, 17, 1-9.

HaRLOW, H. F., \& HaRLow, M. K. (1965). The affectional systems. In A. M. Schrier, H. F. Harlow, and F. Stollnitz (Eds.), Behavior of non-human primates (Vol. 2). New York: Academic Press.

Kummer, H. (1971). Primate societies: Group techniques of ecological adaptation (pp. 287-333). Arlington Heights, IL: Harlan Davidson.

La Freniere, P., Strayer, F. F., \& Gauthier, R. (1984). The emergence of same-sex affiliative preferences among preschool peers: A developmental/ethological perspective. Child Development, 55, 1958-1965.

LANCASTER, J. B. (1971). Play-mothering: The relations between juvenile females and young infants among free-ranging vervet monkeys ( $\mathrm{Cer}$ copithicus aethiops). Folia Primatologica, 15, 161-182.

LINDBURG, D. G. (1969). Rhesus monkeys: Mating season mobility of adult males. Science, 166, 1176-1178.

LINDBURG, D. G. (1971). The rhesus monkey in North India: An ecological and behavioral study. Primate Behavior, 2, 1-106.

MACCOBY, E., \& JACKLIN, C. N. (1974). The psychology of sex differences. Stanford, CA: Stanford University Press.

MitCHELL, G. (1979). Behavioral sex differences in nonhuman primates. New York: Van Nostrand Rheinhold.

Nicolson, N. A. (1987). Infants, mothers and other females. In B. B.
Smuts, D. L. Cheney, R. M. Seyfarth, R. Wrangham, and T. Struhsaker (Eds.), Primate societies (pp. 330-342). Chicago: University of Chicago Press.

PolRIER, F. (1977). Introduction. In S. Chevalier-Skolnikoff \& F. Poirier (Eds.), Primate biosocial development (pp. 1-39). New York: Garland Publishing.

Rowell, T. E., Hinde, R. A., \& SPEncer-Boothe, Y. (1964). 'Aunt'infant interaction in captive rhesus monkeys. Animal Behaviour, 12, 219-226.

SEYFARTH, R. M. (1980). The distribution of grooming and related behaviours among adult female vervet monkeys. Animal Behaviour, 28, 798-813.

SmUTs, B. B. (1987). Gender, aggression and influence. In B. B. Smuts, D. L. Cheney, R. M. Seyfarth, R. Wrangham, \& T. T. Struhsaker (Eds.), Primate societies (pp. 400-412). Chicago: University of Chicago Press.

SPENCER-BOOTH, Y. (1968). The behaviour of group companions toward rhesus monkey infants. Animal Behaviour, 16, 541-557.

Strayer, F. F., Leclerc, D., \& Blicharski, T. (1987). Age and gender differences in agonistic activity during the preschool years. In F. F. Strayer \& E. Moss (Eds.), The development of social and representational tactics during early childhood (Annual Research Rep. 19861987; pp. 34-40). Montréal, Quebec: Laboratoire d'Ethologie Humaine, Departement de Psychologie, Université du Quebec à Montréal.

TIEGER, T. (1980). On the biological basis of sex differences in aggression. Child Development, 51, 943-963.

VeSSEY, S. H., \& MEIKLE, D. B. (1984). Free-living rhesus monkeys: Adult male interactions with infants and juveniles. In D. M. Taub (Ed.), Primate patemalism (pp. 113-125). New York: Van Nostrand Reinhold.

Wallen, K., Bielert, D. F., \& Slimp, J. C. (1977). Foot-clasp mounting in the prepubertal rheus monkey: Social and hormonal influences. In S. Chevalier-Skolnikoff \& F. E. Poirier (Eds.), Primate bio-social development (pp. 439-462). New York: Garland Press.

WALlen, K., Goldfoot, D. A., \& Goy, R. W. (1981). Peer and maternal influences on the expression of foot-clasp mounting by juvenile male rhesus monkeys. Developmental Psychobiology, 14, 299-309.

(Manuscript received February 29, 1988; revision accepted for publication August 1, 1988.) 